\title{
Avaliação da eficiência de extratos de plantas nativas da caatinga sobre o controle da podridão seca (Lasiodiplodia theobromae) em cachos da videira cv. Itália
}

\author{
Georgia de Souza Peixinho ${ }^{1}$, Caio Márcio Guimarães Santos², Valtemir Gonçalves Ribeiro ${ }^{3}$, Edna Peixoto da Rocha \\ Amorim $^{4}$, Jaciara de Souza Bispo ${ }^{1}$, Valdeir Nunes Carvalho ${ }^{4}$
}

\begin{abstract}
${ }^{1}$ Mestranda do Programa de Pós-graduação em Agronomia: Horticultura Irrigada (PPGHI), pela Universidade do Estado da Bahia (UNEB)/ Departamento de Tecnologia e Ciências Sociais (DTCS), Juazeiro- BA, CEP 48905-680. ${ }^{2}$ Instituto Federal Pernambucano (IF-SERTÃO), PetrolinaPE, Zona Rural CEP 56314-520. ${ }^{3}$ PPGHI-UNEB/DTCS, ${ }^{4}$ Universidade Federal de Alagoas-.Centro de Ciências Agrárias, Rio Largo-AL, CEP 57080-000
\end{abstract}

Autor para correspondência: Georgia Souza Peixinho (geopeixinho@gmail.com)

Data de chegada: 15/03/2016. Aceito para publicação em: 24/02/2017.

$10.1590 / 0100-5405 / 2166$

\section{RESUMO}

Peixinho, G.S.; Santos, C.M.G.; Ribeiro, V.G.; Amorim, E.P.R.; Bispo, J.S.; Carvalho,V.N.. Avaliação da eficiência de extratos de plantas nativas da caatinga sobre o controle da podridão seca (Lasiodiplodia theobromae) em cachos da videira cv. Itália. Summa Phytopathologica, v.43, n.2, p.155-157, 2017.

Com a realização deste trabalho objetivou-se verificar o controle de $L$. theobromae através da utilização de extratos vegetais. Inicialmente, foi avaliada a inibição do crescimento micelial de $L$. theobromae em placas de Petri contendo o meio BDA suplementado com os extratos de Boldo Baiano, Jurema Preta, Pata de Vaca e Pau-ferro, nas concentrações 10, 20 e 30\%, para todos os extratos. Posteriormente, foram realizados dois experimentos in vivo com o objetivo de avaliar o efeito direto e protetor dos extratos vegetais testados in vitro sobre a intensidade da podridão seca em cachos da videira cv. Itália, utilizando-se a concentração de $30 \%$, sendo a água destilada esterilizada (ADE) utilizada como testemunha. Os resultados mostraram que extratos de Pau-ferro, Pata de vaca, Jurema preta e Boldo baiano com concentrações de $30 \%$ inibiram o crescimento micelial em 85,$6 ; 83,3 ; 85,6$ e $88,9 \%$, respectivamente, contudo, os extratos testados não foram eficientes para inibir a incidência e a severidade da doença.

Palavras-chave: controle alternativo, doenças fúngicas, extratos vegetais

\section{ABSTRACT}

Peixinho, G.S.; Santos, C.M.G.; Ribeiro, V.G.; Amorim, E.P.R.; Bispo, J.S.; Carvalho,V.N.. Evaluating the efficiency of extracts from plants native to caatinga on dry rot (Lasiodiplodia theobromae) control in bunches of grape cv. Itália. Summa Phytopathologica, v.43, n.2, p.155-157, 2017.

This study aimed to verify $L$. theobromae control by using plant extracts. Initially, L. theobromae mycelial growth inhibition was evaluated on Petri dishes containing PDA medium supplemented with extracts of "boldo baiano", "jurema preta", "pata-de-vaca" and "pau-ferro" at the concentrations of 10, 20 and $30 \%$ for all extracts. Afterwards, two in vivo experiments were carried out to evaluate the direct and protective effect of the plant extracts tested in vitro on dry rot intensity in bunches of grape cv. Itália, using the concentration of $30 \%$, while sterile distilled water (ADE) was adopted as control. Results showed that extracts of "pau-ferro", "pata-de-vaca", "jurema preta" and "boldo baiano" at concentrations of $30 \%$ inhibited mycelial growth by $85.6,83.3,85.6$ and $88.9 \%$, respectively; however, the tested extracts were not efficient in inhibiting the disease incidence and severity.

Keywords: Alternative control, fungal diseases, plant extracts

Doenças causadas por fungos são considerados como uma das principais causas de perdas na fase de armazenamento e comercialização de frutas tropicais. Dentre as enfermidades que acometem a videira, a podridão seca da uva (L. theobromae (Syn. = Botryodiplodia theobromae) merece atenção por tratar-se de uma doença que se expressa frequentemente na fase final de maturação, reduz a vida útil de prateleira, diminui a produção, desqualifica as frutas e aumenta os custos de produção, sendo o seu controle ainda um desafio (10).

Visando extinguir e/ou substituir os agrotóxicos por produtos alternativos, muitos pesquisadores vêm realizando estudos que revelem alternativas de tratamentos, seja para melhorar a qualidade desses alimentos, seja para o controle de fitopatógenos (9). Assim, realizouse este trabalho com o objetivo de estudar o controle da podridão seca da uva através da utilização dos extratos vegetais de Boldo Baiano (Vernonia condensata), Jurema Preta (Mimosa tenuiflora), Pata de Vaca (Bauhinia forficata) e Pau-ferro ( Caesalpinia férrea).
Os experimentos foram conduzidos no laboratório de Pós-colheita do Instituto Federal do Sertão Pernambucano (IF - Sertão), Campus Petrolina, Zona Rural e no laboratório de Fitopatologia, Centro de Ciências Agrárias (CECA) da Universidade Federal de Alagoas (UFAL), em Rio Largo.

No laboratório de Pós-colheita (IF- Sertão), os extratos foram adicionados ao meio de cultura BDA, fundente $\left(45-50^{\circ} \mathrm{C}\right)$ e vertidos em placas de petri de $9 \mathrm{~cm}$ de diâmetro, para cada combinação/ concentração de extrato/fungo: 10, 20 e 30\% para os extratos de Boldo baiano ( $V$. condensata Baker), Jurema preta (M. tenuiflora) Pata de vaca (Bauhinia spp.) e Pau-ferro (C. ferrea) e ADE (testemunha). Todos os extratos foram esterilizados em luz UV por 30 minutos antes de serem adicionados ao meio autoclavado (1). No centro de cada placa foi depositado um disco de meio BDA, de $0,6 \mathrm{~cm}$ de diâmetro, contendo crescimento micelial fúngico retirado das bordas da colônia do patógeno. Após cinco dias de incubação das placas à temperatura 
de $28^{\circ} \mathrm{C}$ e fotoperíodo de 12 horas, foi determinado o diâmetro médio da colônia tomado no reverso das placas de petri, através da medição em dois sentidos diametralmente opostos e, por comparação com o crescimento das colônias nas placas testemunhas, calculou-se a percentagem de inibição do crescimento micelial (P.I.C.) (5). O delineamento experimental utilizado foi o inteiramente casualizado, com 13 tratamentos e 5 repetições (placas). Os valores obtidos foram submetidos a análise de variância, teste $\mathrm{F}$, e quando os efeitos de tratamentos apresentarem diferença significativa $(P<0,01)$ as médias foram comparadas por meio do teste de regressão.

No Laboratório de Fitopatologia (UFAL) foram realizados testes pós- colheita. Na avaliação do efeito direto dos extratos sobre o desenvolvimento de $L$. theobromae, cachos de uva da cv. Itália foram inoculados com o patógeno, realizando-se ferimentos nas bagas com o uso de lâminas esterilizadas, direcionando-se, em seguida, jatos de suspensão de conídios $\left(10^{5}\right.$ con. $\left.\mathrm{mL}^{-1}\right)$ para cada cacho, e, após $4 \mathrm{~h}$, foram aspergidas as soluções de extratos vegetais testadas in vitro, nas concentrações de 30\%, utilizando-se ADE como testemunha (Ensaio 1). As pulverizações foram realizadas com jatos direcionados aos cachos, aplicando-se $10 \mathrm{~mL}$ da solução por cacho, utilizando-se a mesma metodologia para todos os tratamentos. Com o objetivo de avaliar o efeito protetor dos extratos, os cachos foram aspergidos com solução de extratos vegetais, nas mesmas concentrações e testemunha, e após 4 horas foram inoculados com o fungo L. theobromae (Ensaio 2). Nos ensaios os cachos foram dispostos sobre papel absorvente para retenção do excesso de umidade e secagem sob ventilação e permaneceram a
$25 \pm 1{ }^{\circ} \mathrm{C} / 85-95 \%$ UR até o momento da inoculação. Os cachos que haviam sido inoculados quatro horas antes e depois do tratamento foram igualmente acondicionados em sacos plásticos e mantidos a $25 \pm 1^{\circ} \mathrm{C} / 80$ 90 \% UR, por 48 horas (câmara úmida) e avaliados após um período de seis dias, quanto à incidência e severidade perante escala de notas adaptada para Lasiodiplodia theobromae (3).

A escala de notas adotada para avaliação da severidade da doença variou de 1 a 6 , com base na área da lesão, correspondendo aproximadamente a 2, 5, 10, 20, 30 e 50 \% da área da baga lesionada, respectivamente. Os resultados foram expressos em índice de doença calculado através da fórmula: $\operatorname{ID}(\%)=\{[(\mathrm{n} 1 * 1)+\ldots+(\mathrm{n} 6 * 6)] *(6 * \mathrm{~N})-$ $1\} * 100)$. O delineamento experimental utilizado foi inteiramente casualizado, com cinco tratamentos e cinco repetições, cada repetição composta por 10 bagas, para cada ensaio. Os dados obtidos foram submetidos à análise de variância e as médias comparadas entre si pelo teste Tukey, a $5 \%$ de probabilidade.

De acordo com os dados apresentados na Figura 1, os extratos vegetais de Boldo baiano e Pau-ferro, nas concentrações de 10\%, não diferiram estatisticamente da testemunha. Os demais extratos, em todas as concentrações, foram capazes de inibir o crescimento micelial de $L$. theobromae, com variações na porcentagem de inibição: os extratos de Pau- ferro, Pata de vaca, Jurema preta e Boldo baiano proporcionaram inibições de 85,$6 ; 83,3 ; 85,6$ e $88,9 \%$, nas concentrações de $30 \%$, respectivamente, e inibições de 78,9; 78,9; 80 e $75,6 \%$, nas concentrações de $20 \%$.

Borges et al. (2) testando extrato aquoso de Jurema preta,

\section{Pau Ferro}

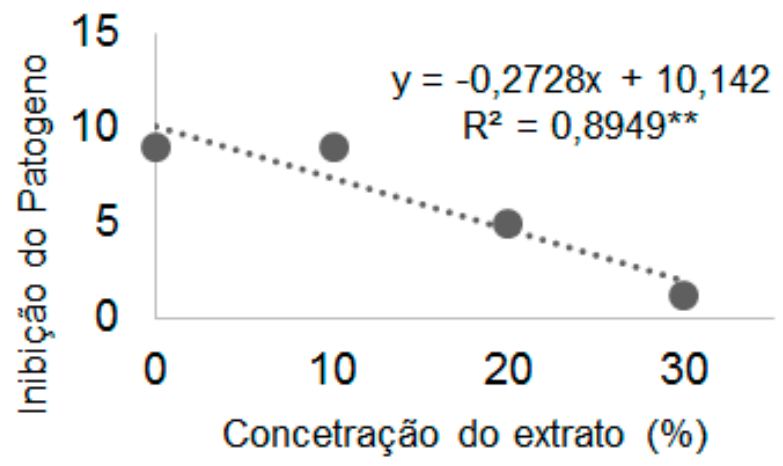

Jurema Preta

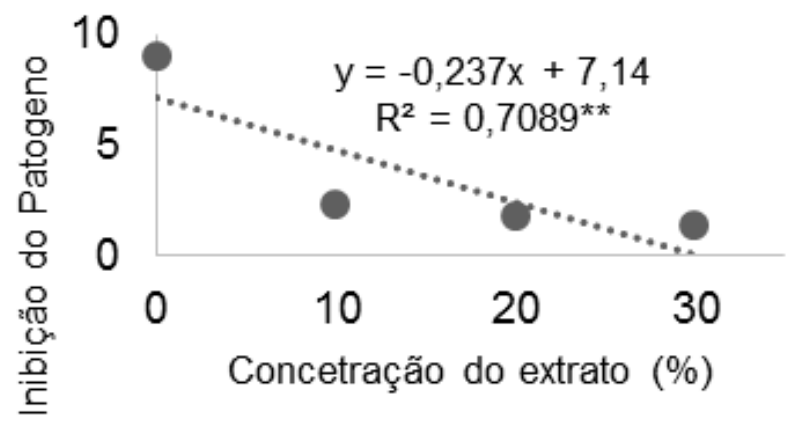

\section{Pata de Vaca}

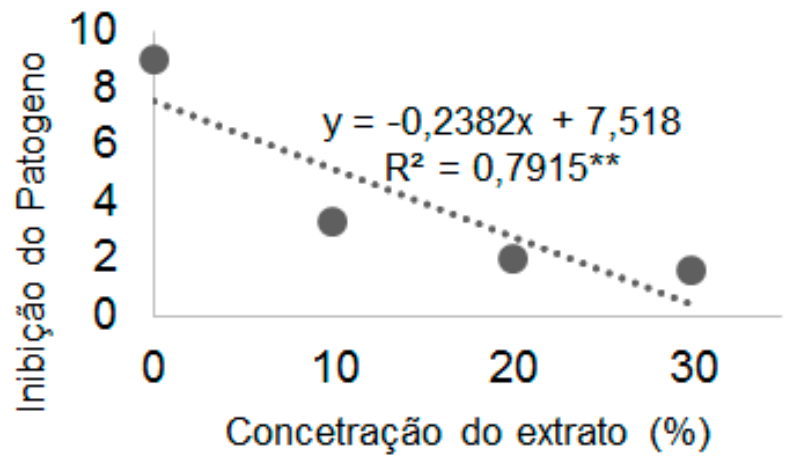

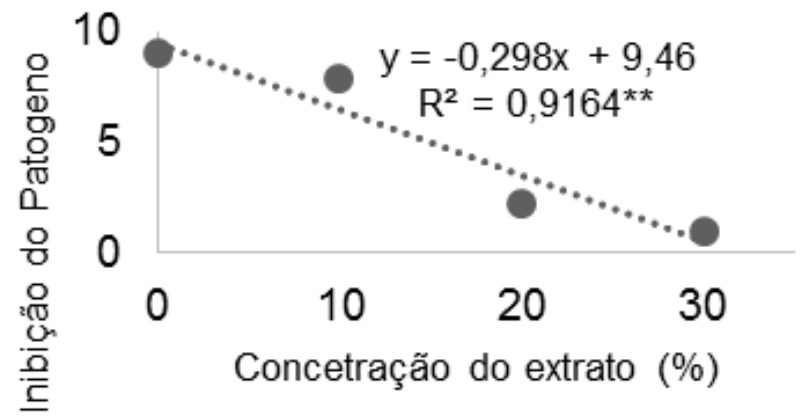

Figura 1. Efeito dos extratos vegetais como indutores de resistência sobre o crescimento micelial de L. theobromae. 
Tabela 1. Efeito dos extratos vegetais sobre a incidência e a severidade (ações curativas e preventivas) da podridão seca ( $L$. theobromae) em cachos da videira cv. Itália.

\begin{tabular}{lcccc}
\hline & Incidência Prev. & Severidade Prev. & Incidência Curat. & Severidade Curat. \\
\hline Pau ferro 30$\} \%$ & $9.0 \mathrm{a}$ & $5.9 \mathrm{a}$ & $1.0 \mathrm{a}$ & $6.0 \mathrm{a}$ \\
Pata de vaca $30 \%$ & $9.0 \mathrm{a}$ & $5.9 \mathrm{a}$ & $0.9 \mathrm{a}$ & $5.6 \mathrm{a}$ \\
Jurema Preta $30 \%$ & $10.0 \mathrm{a}$ & $5.7 \mathrm{a}$ & $0.8 \mathrm{a}$ & $6.0 \mathrm{a}$ \\
Boldo baiano $30 \%$ & $10.0 \mathrm{a}$ & $6.0 \mathrm{a}$ & $1.0 \mathrm{a}$ & $6.0 \mathrm{a}$ \\
Testemunha & $10.0 \mathrm{a}$ & $6.0 \mathrm{a}$ & $0.9 \mathrm{a}$ & $6.0 \mathrm{a}$ \\
\hline
\end{tabular}

Médias seguidas por mesma letra, não diferem entre si, pelo teste de Tukey a 5\% de probabilidade.

observaram efeito fungiestático/fungitóxico, inibindo-se $100 \%$ da germinação de $A$. cucumerina a partir da concentração de $2,5 \mathrm{mg} \mathrm{mL}^{-}$ ${ }^{1}$, e em mais de $50 \%$ desde a concentração de $0,5 \mathrm{mg} \mathrm{mL}^{-1}$. Dentre os tratamentos testados para redução do desenvolvimento das colônias de Phomopsis phaseoli var. sojae, o extrato de Boldo baiano apresentou-se insatisfatório na redução do desenvolvimento das colônias, segundo Pastro et al. (7). Celoto et al. (4) avaliaram o efeito de extratos de 22 espécies de plantas sobre o crescimento micelial e germinação de esporos de $C$. gloeosporioides e verificaram que os extratos aquosos de Eucalipto (E. citriodora), Pata-de-vaca (Bauhinia spp) entre outros, inibiram em mais de $90 \%$ a germinação de esporos.

Todos os extratos testados (Ensaio 1 e 2) não foram eficientes no controle da podridão seca em cachos da cv. Itália, haja vista que nenhum tratamento diferiu estatisticamente da testemunha (Tabela 1).

Ramos et al. (8), testando os extratos vegetais de Pau-ferro (C. ferrea), Angico (A. colubrina) nas concentrações de 500, 1000, 1500 e $2000 \mathrm{mg} \mathrm{l}^{-1}$, não observaram a inibição do crescimento de $F$. guttiforme em frutos de abacaxi (A. comosus). Extratos de Juremapreta $(M$. tenuiflora) originados de cascas e raízes controlaram o desenvolvimento da Mancha-de-alternária em mudas de melancia, cultivadas em ambiente controlado, não havendo interação entre as concentrações e os extratos no controle da doença (2). Karavaev et al. (6) observaram que tanto este como o extrato obtido de Pata-de-vaca (Bauhinia sp.) foram capazes de inibir a germinação de conídios de $E$. graminis e urediniósporos de $P$. graminis, agentes causais do oídio e ferrugem-do-colmo em trigo, respectivamente.

Com respaldo nos resultados obtidos com o presente trabalho, sobre a eficácia dos extratos na redução do crescimento micelial de $L$. theobromae, verifica-se a possibilidade do uso desses extratos vegetais para um controle alternativo desta doença na cultura da videira cv. Itália. No entanto, são necessários mais estudos para se determinar doses adequadas e formas de melhorar o aproveitamento desses extratos.

\section{REFERÊNCIAS}

1.Agrios, G. N. Plant pathology. 5.ed. Burlington :Elsevier Academic Press, 2005.

2.Borges, I.V.; Peixoto, A.R.; Cavalcanti, L.S., Lima, M.A.G.; Silva, M.S. Extratos de jurema preta no controle de mancha-de-alternária em melancia. Revista Caatinga, Mossoró, v. 26, n. 3, p. 36 - 45, jul.- set., 2013.

3.Camili, E. C.; Benato, E. A.; Pascholati, S. F.; Cia, P. Avaliação de quitosana, aplicada em pós-colheita, na proteção de uva 'Itália' contra Botrytis cinerea. Summa Phytopathologica, Botucatu, v.33, p.3, p.215-221, 2007.

4.Celoto, M. I. B.; Papa, M. F. S.; Sacramento, L. V. S.; Celoto, F. J. Atividade antifúngica de extratos de plantas a Colletotrichum gloeosporioides. Acta Scientiarum Agronomy, Maringá, v. 30, n. 1, p. 1- 5, 2008.

5. Edgington, L.V.; Khew, K.L.; Barron, G.L..Fungitoxic spectrum of benzimidazole compounds. Phytopathology, Reino Unido, 61:42-44. 1971.

6.Karavaev, V.A. et al. Antifungal activity of aqueous extracts of the leaves of cowparsnip and comfrey. Biology Bulletin, Chicago, v.28, n.4, p.365370, 2001.

7.Pastro, D.C., Pascuali, L.C., Sandri, D.O., Zela, S.P., Silva, F.D. Diagnóstico de extratos vegetais com potencial para o controle fúngico. In: Enciclopédia Biosfera. Goiânia: Centro Científico Conhecer - Goiânia, v.8, N.14;394 p. 2012.

8. Ramos, E. P.; Souza, W.C.O.;.Nunes, M.C.; Nascimento, L.C. Métodos alternativos no manejo da fusariose do abacaxizeiro 'Pérola'. In: Congresso Brasileiro de Processamento mínimo e Póscolheita de frutas, flores e hortaliças, 001. Anais. Aracaju-SE. 2015.

9.Souza Júnior, I.T; Sales, N.L.P; Martins, E.R. Efeito fungitóxico de óleos essenciais sobre Colletotrichum gloeosporioides, isolado do maracujazeiro amarelo. Revista Biotemas, Florianópolis, v.22, n.3, 2009.

10.Tavares, S.C.C.H. Epidemiologia e manejo integrado de Botryodiplodia theobromae - situação atual no Brasil e no mundo. Fitopatologia Brasileira. Brasília, 27: 46-52. 2002. 